\title{
Living with flooding: Brisbane's approach to floodplain management
}

\author{
S. Pennisi \& O. Perera \\ Brisbane City Council, Australia
}

\begin{abstract}
Brisbane is Australia's third most populous city after Melbourne and Sydney and is the capital city of the State of Queensland. The long meandering Brisbane River flowing through the heart of the city makes Brisbane a green, healthy and subtropical city, earning its ranks among the most liveable cities in the world. Brisbane has faced many flood related challenges since the beginning of the 19th century through to the 21st century. Brisbane grew rapidly after the Second World War and the city's approach to flood risk management focused on land use planning and structural flood mitigation solutions such as pipes. After Brisbane experienced large flood events in 1974 and 2011, Brisbane City Council (Council) adopted a progressive and holistic approach to ensure residents and businesses are safe, confident and ready for flooding. Council's flood risk management strategy, 'FloodSmart Future 2012-2031' (the Strategy), sets out a hazard based land use planning approach through the 'Brisbane City Plan 2014' (City Plan 2014) achieving much needed flood resilient outcomes for the city. This paper describes the four strategic principles the city embraced under the Strategy. The tools Council's project team used during the strategy and individual flood product development will be discussed in this paper together with the use of governance and communication frameworks. Working closely with stakeholders and industry groups to ensure robust consultation with Brisbane's community members and elected representatives has been a formula for success behind the implementation of the range of flood risk management tools by Council including FloodWise Property Reports (FWPR), Flood Awareness Maps (FAM) and the City Plan Flood Overlay Code.

Keywords: floodplain management, flood risk, flood management strategy.
\end{abstract}




\section{Introduction}

Brisbane City Council (Council) is the largest local government in Australia, serving a population of approximately 1.15 million people living across 1370 $\mathrm{km}^{2}$ of land. The primary waterbody traversing Brisbane is the Brisbane River of which approximately $114 \mathrm{~km}$ flows through the Brisbane City local government region with a catchment area of approximately $13,570 \mathrm{~km}^{2}$. There are 35 creek catchments in Brisbane draining into the Brisbane River and ultimately to Moreton Bay. Average annual rainfall in Brisbane is about $1148 \mathrm{~mm}$ and average maximum and minimum temperatures are $260^{\circ} \mathrm{C}$ and $160^{\circ} \mathrm{C}$ respectively [1]. The subtropical climate in Brisbane and its proximity to a number of islands make it one of the most liveable cities in the world, attracting people from all corners for study, work and lifestyle.

Council's best practice flood risk management approach plays a prominent role in supporting Brisbane's increasing population and ever growing economy and it has enabled the achievement of the best possible flood resilient outcomes over the years through a number of measures implemented by Council. These measures include flood planning policy and development assessment, community education and awareness of flooding, the construction of flood mitigation assets and flood emergency management.

\section{Historical flood planning and development: a snap shot}

European settlement of Brisbane occurred in the 1800s and the regulation of development in the local government area commenced around 1924. There have been many Brisbane River floods, most notably the large floods in 1893, 1974 and 2011. There has also been flooding in the various creeks, waterways and overland flow paths due to intense shorter duration localised rainfall. The first Town Plan for Brisbane, approved in 1965 [2], was also the first effective planning scheme for the local government area and shaped the city's early residential built form to increase resilience to flooding. It introduced development guidelines specific to 'Drainage Problem Areas' defined as land which is low lying, affected by floods or difficult or expensive to drain. Since the 1960s, the Council has measured and kept records of flood levels from significant flood events. Furthermore, in the early 1970s, around the time of the 1974 floods, computer models of creek catchments and flow paths were being developed. Council began a process of mapping modelled design flood extents in the form of Flood Regulation Lines (FRLs) as a strategic land use planning approach. FRLs restricted development from occurring in areas subjected to unacceptable risks from flooding. The FRLs were set on the requirement that development occurring in the relevant catchment would not increase flood levels by more than $150 \mathrm{~mm}$ (up to the $1 \%$ Annual Exceedance Probability (AEP) flood) upstream or downstream of the site.

The 1974 flood itself provided the catalyst for a rapid growth in flood modelling of Brisbane's creek catchments. Flood modelling became imperatively useful to estimate design flood levels in order to consistently calculate flood risk 
across the city and determine appropriate measures of mitigation required, flood damages and potential community benefits. The subsequent 1978 Town Plan introduced mapping titled 'Areas Subject to Flooding' which highlighted areas affected by the 1974 floods and provided a minimum habitable floor level for all development in those areas. Further flood planning and development for Brisbane saw the 1994 'Brisbane Waterways' policy introducing FRL and FRL mapping as development assessment criteria for limiting development on floodplains for both creek and River flooding. This was later included in 'City Plan 2000' as the mapping of Waterway Corridors. City Plan 2000 [3] also introduced an additional freeboard for habitable floor levels as a factor of safety. The freeboard was in addition to the designated Defined Flood Level (DFL) or $1 \%$ AEP flood. The Lord Mayors Taskforce on Suburban Flooding established in 2005 looked at all possible ways of reducing the impacts of flooding including mitigation works. The provision of free and reliable flood reports made its way as an online service from 2005. The January 2011 flood brought about the integration of a number of flood and future flood management activities to significantly increase the resilience of the city.

\subsection{Flood information readiness}

During the 1960s recorded (historic) flood level data was made available to the public via a phone service and the recorded data (debris marks) was stored in street directories. During the 1970s and 1980s, this information along with the recorded levels from the January 1974 floods, contributed to a development of series of 4-chain to the inch flood maps. An inundation line representing an envelope of peak recorded flooding was also shown on the maps. These maps were kept at a publicly accessible flood counter. Phone calls and written requests from the public were also dealt with. By the early 2000s, the majority of Brisbane's more significant creeks had been modelled with much work completed during the 1990s. Flood studies were becoming more readily available during the mid-1990s and Flood Regulation Lines became available to the public on standardised flood forms. The design flood level data was included in Council's GIS system as flood cell extents, flood cell details and corresponding levels stored in spreadsheets. Council Flood Studies were placed in the public library system from 2004 and the property flood reports were freely available to public from 2005. The manual process of filling in flood reports for customers became automated and accessible on line in 2008. Formally known as the 'Be FloodWise' Property Report, the report was a flagship product for the 'Be FloodWise' community education campaign aimed at familiarising property owners with their flood risks. The campaign included access to free Flood Flag Maps showing a Defined Flood Event (DFE) for River, 1\% AEP flood for creek and storm tide flood inundation. 


\section{Council's latest approach to flood management}

\subsection{FloodSmart Future Strategy: safe, confident and ready}

Brisbane City Council's 'FloodSmart Future Strategy 2012-2031' [4] sets out the overarching floodplain risk management principles for the city of Brisbane. The Strategy aims to realise Council's vision for flood risk management, "Living with Flooding in our city - we are safe, confident and ready".

Brisbane is no different to many cities in the world where early settlements blossomed in floodplains and flooding was expected as part of a natural phenomenon during extreme climatic conditions. Building on from the work Council had been doing since the 1960s to guide new developments in the floodplain, the Strategy provided a framework to plan and prepare for potential flooding enabling Council staff to respond effectively and help affected residents to recover quickly when flooding did occur. The Strategy was developed by integrating a number of existing and emerging flood risk management measures including structural flood mitigation, hazard based land use planning, interactive flood information and robust flood emergency management (Figure 1). These measures help manage the full range of possible flood events in Brisbane, including more frequent flash flood events that occur on an annual basis during the summer storm season which cause nuisance flooding, as well as rarer events like January 1974 and January 2011 Brisbane River floods which resulted in extensive damage across the city.

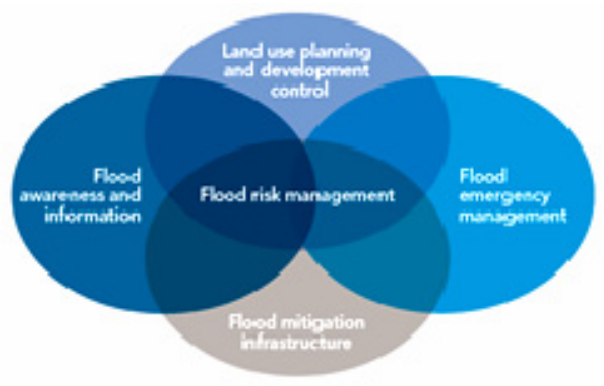

Figure 1: Four strategic flood risk management tools [4].

There were specific drivers that underpinned the development of The Strategy including:

- A simple and easy to understand flood management vision - "Living with Flooding in our city - we are safe, confident and ready".

- Supporting the increasing population and sustainable economic development - it is inevitable that a larger proportion of economic activities in Brisbane are either taking place inside the floodplain or have direct impacts from potential flooding elsewhere. 
- Embracing flood risk management - to depart from traditional 1 in 100 year flood line approach and acknowledge the presence of a full spectrum of potential flood events from all sources of flooding; Brisbane River, creeks, overland flow and storm tide.

- A city built on a floodplain needs to adopt a flood resilient lifestyle Brisbane has experienced flooding previously and it will continue to happen. Therefore the most realistic measure would be to adopt a flood resilient lifestyle and change the way people think about flooding.

- Support planning, decision making and investment - as the fiscal liability for maintaining essential services continue to grow within local governments, prioritising investments is extremely challenging. A tool for making informed planning and investment decisions such as more investment on flood awareness and education compared to constructing flood mitigation assets that have inherent residual risks which cannot be eliminated.

- The 2011 Queensland Floods Commission of Inquiry (QFCoI) - final report and its recommendations called for an approach to flood management based on best practice floodplain management planning.

One of the key outcomes expected from the Strategy was to adopt a riskbased approach to flood management by understanding the behaviour and consequences of flooding across the full range of probabilities. A risk based approach, as opposed to planning for traditional ' 1 in 100 year' flood event, ensured the safety of people while enabling the responsible development of the city. The success of the Strategy development process was achieved through various avenues, including strong input from a wide range of internal Council staff representing a number of civic administrational areas, including land use planning, environmental management, infrastructure, waste services, public transport and emergency management. Stakeholder input coupled with professional advice resulted in a visually appealing, simple and plain English flood management strategy document which could otherwise have been a complex, technical and difficult to explain.

The Strategy was structured around two over-arching and high level strategic outcomes:

1. A risk-based approach to flood management: Understanding the behaviour and consequences of flooding from all sources, across a range of probabilities.

2. An integrated and adaptive approach: Implementing integrated and adaptive approaches to total water cycle management, including flooding.

The Strategy also includes outcomes representing the four flood risk management tools:

1. Smart planning and building: Shaping the City's built form to increase our resilience to flooding.

2. An educated and resilient community: Promoting community understanding of flooding to encourage readiness.

3. World class response and recovery: Further develop our capacity to respond to and recover from flood events. 
4. Maintaining and improving our structural assets: Maintaining and investing in flood mitigation assets to support the city's economic growth.

The Strategy offered a set of tools for decision makers to be more flexible in their flood risk management investment to weigh up the merits of various flood risk management options.

Over the last five years, Council has spent over $\$ 600$ million towards flood risk management, including stormwater drainage upgrades, flood modelling and floodplain management studies, backflow prevention devices, purchasing frequently flood affected residential properties, and online flood information for residents and businesses. Compared to other countries in the world Australia utilises a larger proportion of flood risk management funding on flood disaster management and recovery i.e. responding to and recovering from flood events. Therefore, the linkage between the flood risk management tools in Council's flood management strategy with Queensland's disaster management approach of PPRR - prevention, preparedness, response and recovery [5], was deliberately included in the Strategy. Following the endorsement of the Strategy in 2013 Council continues to achieve the outcomes of the four strategic flood risk management tools as discussed in following sections.

\subsubsection{Smart planning and building}

Smart planning and building for flood resilience is supported by the Brisbane City Plan 2014 [6] Flood overlay code. The primary objective of Council's flood overlay code in the City Plan is to shape the future built form of the city in a way that adapts to flooding and increase the capacity of Brisbane residents and businesses to live with flooding. The City Plan recognises that parts of Brisbane have been built on a floodplain; flooding is a natural part of our environment and it is not possible to completely eliminate flooding in Brisbane. The flood overlay code enables people to address the challenges that flooding brings through hazard based smart land use planning for future development and smart flood resilient building designs. Following the January 2011 Brisbane River flood, Council implemented emergency town planning rules to guide development in suburbs affected by flooding (through the Temporary Local Planning Instrument) which included the following:

- Setting floor levels in homes above either the 2011 flood level or the defined Brisbane River flood level (DFL), whichever was higher of the two.

- Allowing houses in flood-prone areas to be built higher than standard buildings to protect homes from flooding.

These requirements were later integrated into the flood overlay code of City Plan 2014 along with other flood planning provisions. Flood overlay code categorises flood hazard into five Flood Planning Areas (FPA) primarily based on the flood velocity and depth (fig 2). Additionally, the flood overlay code provides guidelines regarding the compatibility of particular land uses to flood hazard based on the vulnerability of the proposed land use activities. FPA's have been made available to the general public through an interactive web based GIS mapping interface that provides property specific flood planning information. 
Flood hazard categories [6] are defined as they apply to each flooding source, river, creek and overland flow.

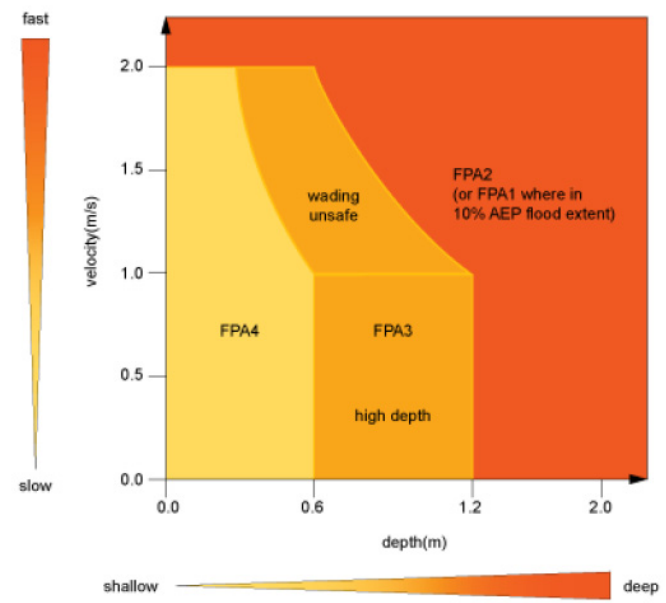

Figure 2: Flood hazard hydraulic categories [6].

The flood overlay code delivers a balanced outcome which recognises the need for new development that protects the safety of the community and minimises property impacts from flooding, while not imposing unnecessary costs on builders and developers. This is achieved by providing clear guidance for any future development in flood affected areas and streamlining the Council assessment process. The flood overlay code, and accompanying Flood Planning Scheme Policy, offer flexibility by providing predetermined acceptable design solutions (such as minimum habitable floor levels, compatible land uses and undercroft clearance heights) or performance based outcomes. By adhering to the predetermined acceptable solutions, developments can reduce the level of assessment required to be undertaken by Council, thus reducing time and cost. If a development is unable to meet the specified acceptable solutions, an alternative solution can be proposed that achieves the performance based outcomes specified in the code. Choosing to proceed with a performance based solution may result in additional assessment requirements, but provides flexibility by allowing suitable alternative design outcomes. The City Plan 2014 Flood Planning Scheme Policy provides detailed guidance about satisfying assessment criteria including how to prepare a Flood Risk Assessment.

The Flood Planning Scheme Policy also provides detailed information about calculating flood planning levels for creeks/waterways and overland flow. Flood planning levels are determined based on the 1\% AEP (and other relevant events) flows assuming a fully developed catchment (an 'ultimate catchment development' scenario). The fully developed catchment considers the potential impact of cumulative infill development and filling outside the "Flood Conveyance Corridor" (FCC). The FCC is modelled as a vertical wall in the 
hydraulic model for design events up to $1 \%$ AEP. The resultant flood heights derived from this model represent the design flood levels. For events greater than the $1 \% \mathrm{AEP}$, it is inappropriate to restrict flood waters as described above and it is not a realistic representation of what would reasonably be expected to occur during a larger flood event. Therefore, the following method for simulating future floodplain conditions for extreme events is applied:

- Topography is extended sufficiently in the computer model to contain anticipated Probable Maximum Flood (PMF) extents.

- Simulate the $1 \%$ AEP flood levels using vertical walls.

- Add a 300mm development freeboard (to derive the 'development level').

The events greater than the $1 \%$ AEP are re-simulated in areas outside the FCC representing the floodplain as filled up to the development level. Ultimate catchment development scenario has little benefit deriving planning levels for the Brisbane River since more than $75 \%$ of the Brisbane River catchment is outside the Brisbane local government area and Brisbane is located at the bottom of the catchment.

Detailed flood level information for a range of AEP's derived from flood studies are made available to the public through the online FloodWise Property Reports (FWPR). Every property in Brisbane is able to download the free FWPR that contains not only the flood levels but also the applicable FPA's together with minimum and maximum ground levels of the property and minimum habitable floor level the building should be designed and built for. The ground levels for each property are kept up to date using Queensland Government's Light Detection and Ranging (LiDAR) surveys.

\subsubsection{An educated and resilient community}

Providing easily accessible flood information is an important component to ensuring an educated and resilient community. Council provides online flood information for residents, businesses and visitors to stay informed and educated. This is a key aspect of Brisbane's flood risk management strategy.

Following the January 2011 Brisbane River flood event, Council produced a 'fit for purpose' city-wide broad scale Flood Awareness Map (FAM). FAM is an online GridFlow tool based on digital elevation modelling. FAM was developed to help inform and educate Brisbane's residents and business. FAM utilises mapping innovations and interactive web-tools to educate the community about the types of flooding across the city and importantly to empower them to be prepared for potential future flooding. FAM presents four zones of flood likelihood (high, medium, low and very low) the source of flooding (river, creek, overland flow and storm tide) and two historical river events (1974 and 2011).

\subsubsection{World class response and recovery}

Communication and education is key in preparing for disasters. Being prepared can help minimise the impacts and create a more resilient community. Each year Council runs a communication campaign - 'All Hazards Brisbane Ready for Summer' - that encourages the community to take action and 'be prepared' to help reduce the risks to their family, pets and property. This campaign uses a 
wide range of channels to reach residents generally and a number of target audiences, and promotes tools and services to help be prepared for a range of natural hazards. Some of the tools available online include Council's:

- Severe Weather Early Warning Alert Service - direct weather alerts to subscribed mobiles and email addresses.

- Interactive Flood Awareness Maps.

- FloodWise Property Report.

- Home readiness checklist.

There are also a number of checklists, fact sheets and videos available, some of which include tips on how to prepare an emergency kit and how to prepare homes and yards for severe weather. Community engagement activities also assist vulnerable communities by providing education on how to be prepared. This enables communities to provide for their own disaster planning, which could include evacuation and household emergency plans.

During and after an event, Council provides information to the community and residents via a number of digital and online channels including community service announcements, social media and text and telephone messages. In significant disaster events, Council with the assistance of other agencies such as State Emergency Service, Police and Fire \& Rescue services undertake door knocking to ensure potentially impacted residents and businesses are informed of the threat. Council coordinate all flood emergency situations through its 24-hour Local Disaster Coordination Centre supported by the Bureau of Meteorology for flood forecasting.

Cleaning-up and temporarily relocating affected communities is a high priority for Council. Disposing of waste and repairing damage is organised through Council in partnership with external agencies and organisations. Council also assists the Queensland Government and external agencies with the relocation, evacuation and temporary housing of residents as well as grant funding applications and funding allocations from the Queensland Government to help with recovery of communities affected by a flood. During the January 2011 flood Council coordinated around 60,000 volunteers to clean-up flood debris and this group of volunteers ultimately earned the title of 'Brisbane Mud Army'.

\subsubsection{Maintaining and improving our structural assets: flood mitigation}

Council has an ongoing program of both structural and non-structural flood mitigation activities across Brisbane. During the January 2011 flood, some parts of Brisbane were affected by water which came up from the river, through the drainage networks, on to the streets and into buildings. This is referred to as backflow flooding and immediately after the flood event Council conducted technical investigations to look at the feasibility of installing backflow devices in areas where backflow flooding occurred. The investigation was required as these devices are not suitable in all situations. A backflow prevention device is designed so that water flows in one direction through piped stormwater systems and minimises water flowing back up stormwater pipes. Backflow prevention devices are effective at averting stormwater flooding in certain circumstances 
only and there is no guarantee of full flooding protection. It was always acknowledged that while these devices reduce the chance of backflow flooding, they cannot prevent other forms such as overland flow or creek flooding. Backflow prevention devices are one of many flood mitigation tools and strategies that Council has implemented to help protect Brisbane from the impacts of flooding.

Council manages more than $270 \mathrm{~km}$ of urbanised open waterways and approximately $2700 \mathrm{~km}$ of natural waterways. This includes $40 \mathrm{~km}$ of natural waterways located along the lower reaches of major creeks which are classified as flood mitigated sections. Flood mitigated sections were generally constructed in 1970s and 1980s to reduce flooding and Council continues to maintain the bed profile of these creek sections to ensure optimum flood conveyance by undertaking de-silting activities and vegetation management. Council's underground stormwater drainage network consists of approximately $2700 \mathrm{~km}$ of pipes or box culverts, 71,000 maintenance holes and 96,000 gullies. Council has an ongoing CCTV inspection program of its drainage network to proactively identify potential failures and siltation. Following the January 2011 floods nearly $500 \mathrm{~km}$ of the stormwater network was inspected and cleaned by Council to remove 22 million litres of sludge that had been accumulated from the flooding which had the potential to compromise the capacity of stormwater drainage network.

Council also implements non-structural flood mitigation works in the form of voluntary buying of residential properties at risk of flooding from $50 \%$ AEP event ( 1 in 2 year flood) and greater. Since 2006 Council has purchased 107 residential properties at risk of flooding equating to close to $\$ 55$ million. Properties purchased under the Voluntary Home Purchase Scheme are used by Council for conservation, drainage easements and parklands and it is Council's policy not to redevelop these flood prone areas for future residential use.

\subsection{Maintaining up to date information}

Brisbane is susceptible to four types of flooding:

1. River flooding - causing high flows of water to rise and flow over river banks which occurs days after the rain has stopped in the upper catchment.

2. Creek flooding - which flows quickly and causes flash flooding of areas around creeks and waterways within hours.

3. Local overland flow flooding - the most common type of flooding in our city, and

4. Storm tide flooding.

For property specific detailed flood level information Council has an ongoing program of flood studies covering all four sources of flooding: creek, storm tide (coastal), overland flow and river. Creek flood studies are mostly undertaken by Council's flood modelling engineers and external consultancies using twodimensional flood modelling software. Council recently completed a coastal flood study and a two dimensional city wide overland flood model is nearing completion. Also as recommended by the QFCoI into 2011 floods, Council is working with the State Government of Queensland and three other local 
governments in the Brisbane river catchment (Ipswich, Somerset and Lockyer Valley) to complete a comprehensive flood study for Brisbane River that takes into account the impacts of dam operations and varied hydrological conditions in the catchment.

To overcome the complex uncertainties within the catchment affecting the flood estimation, the Monte Carlo Simulations (MCS) method was utilised for Brisbane River flood study. The MCS method has the advantage over more 'traditional' approaches towards flood risk analysis in that it explicitly considers all relevant physical processes and associated variables that contribute to flood events [7]. Arguably the Brisbane River flood study is one of the first flood studies in Australia that utilised a comprehensive MCS approach to estimate design flood flows.

\section{Challenges, opportunities, and governance}

Council recognises the need for continuous improvement in flood risk management given the technological advancements in the industry, challenges posed by climate variability and the presence of different layers of management authorities such as Local Government, State Government and Federal Government.

One of the key opportunities in the future of flood risk management in Brisbane would be to have the ability to run real time models to provide flood forecasting for creeks and overland flow paths. Both of these sources of flooding in Brisbane have a very short lead time that makes it challenging to run real-time models with inputs from the Bureau of Meteorology (BoM) including forecast rainfall with a reasonable spatial coverage. Such hydrological inputs could inform the hydraulic models to generate possible flood extents with an adequate lead time for the emergency flood managers to utilise resources effectively.

The widespread use of social media and the availability of mobile devices have provided Council with great opportunities to harness the capabilities of these systems for flood information and warnings through applications (apps) and also to collect flood data with the help of the general public. There are increased uses of mobile devices with the ability of taking georeferenced photographs and videos. Emerging technologies such as drones and autonomous vehicles that have the capability of 3D scanning of the surroundings will change the way we collect data as it ensures safe data collection in hazardous environments such as fast flowing deep flood waters.

Council flood studies have considered the sensitivity of climate variability for each of the creeks to understand the uncertainties and limitations around flood predictions so that appropriate measures such as adequate free board can be applied to reduce the residual flood risk. Maintaining consistency in flood risk management across catchments that span beyond the Council's administrative area is heavily reliant on establishing robust governance that has representation from all stakeholders in all levels of governments, Local, State and Federal. 
Ultimately the success and effectiveness of Brisbane's flood risk management approach will be measured against how well, as a city, we are adapting to living with flooding and how 'safe, confident and ready' we are.

\section{References}

[1] Bureau of Meteorology, Climate statistics for Australian locations, www.bom.gov.au/climate/averages

[2] Brisbane City Council, Queensland Floods Commission of Inquiry Submission Two, 2011

[3] Brisbane City Council, Superseded Brisbane City Plan 2000 www.brisbane.qld.gov.au/planning-building/planning-guidelines-and-tools/ superseded-brisbane-city-plan-2000

[4] Brisbane City Council, Brisbane's FloodSmart Future Strategy Web Site, Brisbane, www.brisbane.qld.gov.au/community/community-safety/disastersemergencies/types-disasters/flooding/flood-policy-plans-projects/brisbanesfloodsmart-future-strategy

[5] Davidge, E. \& Rogencamp, G., A Floodsmart Future - Strategic Flood Risk Management in Brisbane. Proc. of the 53rd Annual Floodplain Management Authorities Conference, Tweed Heads, Australia, pp. 1-9, 2013

[6] Brisbane City Council, Brisbane City Plan 2014, www.brisbane.qld.gov.au/ planning-building/planning-guidelines-tools/brisbane-city-plan-2014

[7] Aurecon Australia Pty Ltd, Brisbane River Catchment Flood Study: Comprehensive Hydrologic Assessment, 2015 